\title{
Article
}

\section{Direct and indirect orthotic management of medial compartment osteoarthritis of the knee}

Jones, R.K., Nester, C.J., Kim, W.Y., Tyson, S., Laxton, P., Jari, S., Johnson, D.S. and Richards, Jim

Available at http://clok.uclan.ac.uk/5636/

Jones, R.K., Nester, C.J., Kim, W.Y., Tyson, S., Laxton, P., Jari, S., Johnson, D.S. and Richards, Jim ORCID: 0000-0002-4004-3115 (2006) Direct and indirect orthotic management of medial compartment osteoarthritis of the knee. Gait \& Posture, 24 (Supp2). S141-S142. ISSN 09666362

It is advisable to refer to the publisher's version if you intend to cite from the work. http://dx.doi.org/10.1016/j.gaitpost.2006.11.098

For more information about UCLan's research in this area go to http://www.uclan.ac.uk/researchgroups/ and search for <name of research Group>.

For information about Research generally at UCLan please go to http://www.uclan.ac.uk/research/

All outputs in CLoK are protected by Intellectual Property Rights law, including Copyright law. Copyright, IPR and Moral Rights for the works on this site are retained by the individual authors and/or other copyright owners. Terms and conditions for use of this material are defined in the policies page.

\section{CLoK}

Central Lancashire online Knowledge www.clok.uclan.ac.uk

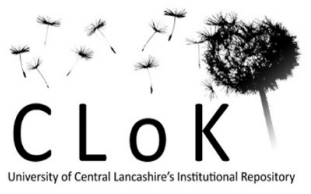


Table 1

Comparison of mean pre- vs. post-operative data for the STFU (short term) and LTFU (long term) follw-up groups $(p<0.05$ significance level)

\begin{tabular}{|c|c|c|c|c|c|c|}
\hline & Pre & Short-term & $p$-value & Pre & Long-term & $p$-value \\
\hline Knee extension at initial contact $\left({ }^{\circ}\right)^{\mathrm{a}}$ & 25.8 & 18.7 & 0.000 & 25.7 & 18.5 & 0.000 \\
\hline Peak knee extension in stance $\left({ }^{\circ}\right)^{\mathrm{a}}$ & 11.5 & 5.3 & 0.000 & 9.3 & 5.4 & 0.062 \\
\hline Pelvic tilt-anterior $\left({ }^{\circ}\right)$ & 19.5 & 22.0 & 0.048 & 17.6 & 19.2 & 0.114 \\
\hline Ankle plantar flexion at initial contact $\left(^{\circ}\right)$ & -10.2 & -4.0 & 0.002 & -8.1 & -4.7 & 0.191 \\
\hline Velocity $(\mathrm{m} / \mathrm{s})$ & 0.99 & 1.07 & 0.008 & 0.90 & 1.02 & 0.006 \\
\hline Stride length (m) & 0.85 & 0.95 & 0.000 & 0.84 & 0.99 & 0.000 \\
\hline Cadence (steps/min) & 143 & 137 & 0.129 & 124 & 123 & 0.696 \\
\hline Normalcy Index & 308 & 136 & 0.000 & 295 & 142 & 0.001 \\
\hline \multirow[t]{2}{*}{ Popliteal angle $\left({ }^{\circ}\right)$} & 49.3 & 35.0 & 0.000 & 48.6 & 38.2 & 0.006 \\
\hline & & $n=45$ limbs & & & $n=26$ limbs & \\
\hline
\end{tabular}

a Positive value $=$ knee flexion.

\section{Discussion}

The results of this study showed that percutaneous hamstring lengthenings were effective at improving knee extension at initial contact for both STFU and LTFU groups. Velocity and stride length were also significantly increased and these effects were maintained at long-term follow up. Increased leg length due to growth was not accounted for in the calculations and therefore caution should be taken with this interpretation. Popliteal angle demonstrated a significant improvement in the STFU and LTFU groups which is contrary to a previous finding [4]. The Normalcy Index demonstrated significant improvement in both the STFU and LTFU suggesting that normalization of gait (overall improvement) was accomplished when PMHL were done in conjunction with other appropriate soft tissue and bony surgeries. This technique minimizes the morbidity (reduces the scarring internally and externally) while maintaining comparable gait results to a group of patients that received open medial hamstring lengthenings [1]. Percutaneous medial hamstring lengthenings could be considered a viable option for lengthening hamstrings in appropriate patients, not only due to its effectiveness in improving gait outcomes, but also because of its simplicity.

\section{References}

[1] DeLuca PA, et al. J Pediatr Orthop 1998;18:712-8.

[2] Damron T, et al. J Pediatr Orthop 1991;11:514-9.

[3] Schutte LM, et al. Gait Posture 2000;11:25-31.

[4] Chang W-N, et al. Gait Posture 2004;19:298-304.

doi:10.1016/j.gaitpost.2006.11.097

\section{PP-030}

\section{Direct and indirect orthotic management of medial com- partment osteoarthritis of the knee}

R.K. Jones ${ }^{\mathrm{a}, *}$, C.J. Nester ${ }^{\mathrm{a}}$, W.Y. Kim ${ }^{\mathrm{c}}$, S. Tyson ${ }^{\mathrm{a}}, \mathrm{P}$. Laxton $^{\text {b }}$, S. Jari ${ }^{\text {c }}$, D.S. Johnson ${ }^{\text {d, J.D. Richards }}{ }^{\mathrm{e}}$

${ }^{\text {a } C e n t r e ~ f o r ~ R e h a b i l i t a t i o n ~ a n d ~ H u m a n ~ P e r f o r m a n c e ~ R e s e a r c h, ~ U n i v e r s i t y ~}$ of Salford, Salford, UK

${ }^{\mathrm{b}}$ Directorate of Podiatry, University of Salford, Salford, UK

${ }^{\mathrm{c}}$ Hope Hospital, Salford, UK

d Stockport NHS Foundation Trust, Stockport, UK

${ }^{\mathrm{e}}$ Allied Health Professions, University of Central Lancashire, Lancashire, UK

\section{Introduction}

Osteoarthritis (OA) is a painful condition and affects approximately $80 \%$ of individuals by the age of 55 [1], with knee OA occurring two times more frequently than OA of the hand or hip [2].The condition is more prevalent in the medial compartment and restricts the daily lives of individuals due to pain and a lack of functional independence. Patients with medial compartment osteoarthritis often have a varus alignment, with the mechanical axis and load bearing passing through this compartment with a greater adduction moment leading to greater pain and progression of osteoarthritis [3]. Surgery for the condition is possible although in some cases, particularly younger patients or those not yet requiring surgery, clinical management remains a challenge. Before surgery is considered, however, conservative management is advocated, though no one treatment has been shown to be most effective, and there are few quality biomechanical or clinical studies. Of the conservative approaches the principal orthotic treatments are valgus knee braces and laterally wedged foot inlays. Studies of knee valgus bracing have consistently demonstrated an associated decreased pain and improved function [4], and greater confidence [5]. A laterally wedged foot inlay has a thicker lateral border and applies a valgus moment to the heel. It is theorised that by changing the position of the ankle and subtalar joints during weight-bearing [6] the lateral wedges may apply a val- 
gus moment across the knee as well as the rearfoot, with the assumed reduction on load in the medial knee compartment [7]. However, there has been no study to directly compare these orthotic treatments in the same study. The aim of this research is to investigate the efficacy of valgus knee braces and laterally wedged foot inlays in reducing the varus knee moment.

\section{Statement of clinical significance}

The study suggests that direct and indirect orthotic management of osteoarthritis can alter the biomechanical function of the knee and thereby reduce the loading on the medial compartment.

\section{Methods}

Eight subjects (four male and four female) (ages 64.8 years (S.D. 6.4) mass $80.8 \mathrm{~kg}$ (9.8), were recruited for the study. Each individual was radiologically diagnosed as having medial compartment osteoarthritis of the knee joint. The study was approved by the Salford Local Ethical Committee with consent given by the participants. The study took place at the University of Salford Gait laboratory. An eight-camera motion analysis system (Qualisys, Proreflex) capturing at $100 \mathrm{~Hz}$ and two bilateral force plates (Kistler) capturing at $200 \mathrm{~Hz}$ were used for the data collection. Marker placement was based on the Calibrated Anatomical System Technique [8] with cluster plates over the shank, thigh, pelvis and foot. Anatomical reference frames were modelled to represent the lower limb as segments in the local coordinate system. Standard footwear was worn for each testing session to ensure no confounding results from differing footwear and the participants performed 10 walking replicates, at a self-selected speed, in two conditions. Each participant wore a laterally wedged foot inlay (Algeos, Liverpool, UK) and a knee valgus brace (OAdjuster, Donjoy Orthopaedics, USA), for a period of 2 weeks in a randomised crossover design. To ensure reliability the foot inlays were manufactured by the same podiatrist, and the same individual fitted all braces. All data were exported to Visual 3D (C-Motion, Inc., USA) where interpolation and low pass filtering $(6 \mathrm{~Hz}$ Kinematic, $15 \mathrm{~Hz}$ Kinetic) was undertaken. The peak knee adduction moment during loading was the primary outcome measure used to compare the two treatments. A repeated measures ANOVA test was performed with post hoc pair-wise comparison with a significance level of $5 \%$, with a bonferroni adjustment to reduce the chance of type- 1 errors.

\section{Results}

The peak knee adduction moment during loading in the laterally wedged foot inlays and valgus knee brace significantly
Table 1

Mean knee adduction moment (1S.D.) during the three conditions $(N=8)$

\begin{tabular}{llll}
\hline Condition & No orthotic & Knee brace & Foot inlay \\
\hline Add moment $(\mathrm{Nm} / \mathrm{kg})$ & $0.58(0.08)$ & $0.52(0.08)$ & $0.47(0.07)$ \\
\hline
\end{tabular}

decreased (Table 1) compared to the no orthotic condition $(P<0.05)$. There was a larger decrease in the laterally wedged inlays than the valgus knee brace. There was no significant difference in walking speed between all three conditions $(P>0.05)$.

\section{Discussion}

The results suggest that both direct (knee brace) and indirect (laterally wedged inlay) orthotic interventions can reduce the adduction moment of the osteoarthritic knee. The results of this study will inform the sample size calculation for a phase II clinical trial to assess the biomechanical effects and clinical consequences of these interventions in people with medial compartment osteoarthritis of the knee.

It is hoped that the clinical efficacy of these treatments can be further defined by evaluating any correlation between the biomechanical, clinical and patient perceived outcomes. Providing biomechanical, clinical and patient based evidence to orthopaedic clinicians may increase the use of orthoses in those patients who are either not suitable for surgery or waiting for surgery. The next stage of the research is to the efficacy of combining both types of conservative treatment (direct and indirect) in the hope this will reduce the knee adduction moment even further.

\section{Acknowledgements}

The authors would like to thanks Algeo's and Donjoy Orthopaedics for their kind support of materials and braces for the study.

\section{References}

[1] Altman R. Am J Med 1987;83:65-9.

[2] Oliveria S, et al. Arthritis Rheum 1995;38:1134-41.

[3] Kaufman KR, et al. J Biomech 2001;34:907-15.

[4] Lindenfeld TN, et al. Clin Orthop 1997;344:240-7.

[5] Richards JD, et al. J Bone Joint Surg [Br] 2005;87B:937-9.

[6] Pollo FE. Am J Knee Surg 1998;11:47-50.

[7] Jones RK, et al. ISB 2005. Cleveland, OH.

[8] Cappozzo A, et al. Clin Biomech 1995;10:171-8.

doi:10.1016/j.gaitpost.2006.11.098 